\title{
Rota-lithotripsy: A combination of rotational atherectomy and intravascular lithotripsy (Shockwaves) as a novel strategy for a rotablation- -resistant lesion in a patient with ST-segment elevation myocardial infarction
}

\author{
Adrian Włodarczak ${ }^{1 *} \odot$, Piotr Rola ${ }^{2} * \odot$, Mateusz Barycki ${ }^{2} \odot$, Barbara Engel $^{2}$, \\ Marek Szudrowicz ${ }^{1} \oplus$, Jan Jakub Kulczycki ${ }^{1} \oplus$, Maciej Lesiak ${ }^{3} \oplus$, Adrian Doroszko ${ }^{4} \odot$ \\ ${ }^{1}$ Department of Cardiology, The Copper Health Centre (MCZ), Lubin, Poland \\ ${ }^{2}$ Department of Cardiology, Provincial Specialized Hospital, Legnica, Poland \\ ${ }^{3} 1^{\text {st }}$ Department of Cardiology, University of Medical Sciences, Poznan, Poland \\ ${ }^{4}$ Department of Internal Medicine, Hypertension and Clinical Oncology, \\ Wroclaw Medical University, Wroclaw, Poland
}

\begin{abstract}
A 71-year-old female was admitted to the documented cath-lab with ST-segment elevation myocardial infarction (STEMI) of the inferior wall. Coronary angiogram revealed acute occlusion of the right coronary artery without other significant lesions (Fig. 1A). Percutaneous coronary intervention (PCI) was performed by the right-radial access, using the JR4.0 (6 F) Guide-Catheter. Initial high-pressure (22 atm.) predilation with a non-compliant balloon $(\mathrm{NCB})$ catheter $2.5 \times 20 \mathrm{~mm}$ was performed (Fig. 1B). Due to incomplete expansion, the size of NCB was decreased to $2.0 \times 15 \mathrm{~mm}(24 \mathrm{~atm}$.) with unfavourable effect (Fig. 1C). Afterwards, we switched to the $7 \mathrm{~F}$ right-radial access (JR 4.0) and despite use of an extra support guidewire, subsequent guide extension and additional anchor-balloon manoeuvre, we were still unable to cross the lesion with the ShockWave Intravascular Lithotripsy (S-IVL) balloon-catheter $(3.5 \times 12 \mathrm{~mm})$. Therefore, we exchanged a guide-
\end{abstract}

wire on the Rotawire-Extra-Support and performed a successful rotational atherectomy (RA) with Rotablator burr size $1.75 \mathrm{~mm}$ (Fig. 1D). Subsequently, a high-pressure (22 atm.) inflation of a $3.5 \times 15 \mathrm{~mm}$ $\mathrm{NCB}$ was performed. Despite lesion preparation with the RA, a significant "dogbone effect" was still observed (Fig. 1E). Hence, we performed the S-IVL using a $3.5 \times 12 \mathrm{~mm}$ catheter. After application of 40 ultrasonic pulses, full expansion was obtained (Fig. 1F). Drug eluting stent $3.5 \times$ $\times 38 \mathrm{~mm}$ (16 atm.) implantation was followed by a $4.0 \times 20 \mathrm{~mm}(20 \mathrm{~atm}$. $) \mathrm{NCB}$ post-dilation. Finally, a satisfying angiographic result was obtained, and was confirmed by the optical coherence tomography (minimal lumen area $8.06 \mathrm{~cm}^{2}$ ) (Fig. 1G-J).

According to available research, we are the very first to present a well-documented successful application of a complex advanced plaque-modifying method (RA+S-IVL bailout PCI) in a subject with STEMI via radial access.

Conflict of interest: None declared

Address for correspondence: Piotr Rola, MD, PhD, Department of Cardiology, Provincial Specialized Hospital Legnica, ul. Iwaszkiewicza 5, 55-220 Legnica, Poland, tel: +48 888272 007, e-mail: piotr.rola@gmail.com

Received: 25.02.2021 Accepted: 5.05.2021

*Equal authorship

This article is available in open access under Creative Common Attribution-Non-Commercial-No Derivatives 4.0 International (CC BY-NC-ND 4.0) license, allowing to download articles and share them with others as long as they credit the authors and the publisher, but without permission to change them in any way or use them commercially. 


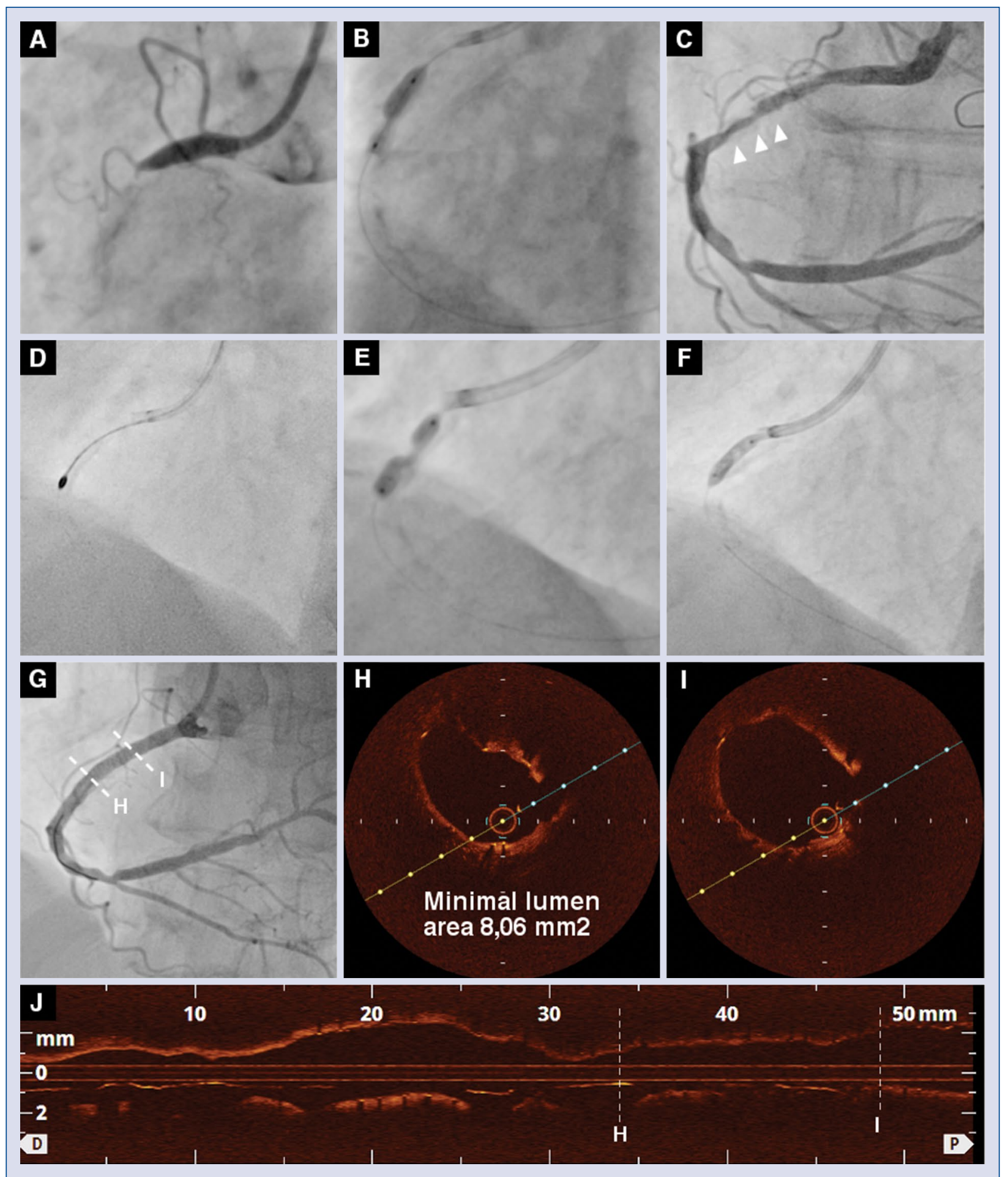

Figure 1. A. initial angiography acute occlusion of right coronary artery (RCA); B. Incomplete expansion of $2.5 \times 20 \mathrm{~mm}$ non-compliant (NC) balloon catheter; C. Angiography after restoring flow to RCA-heavily calcified culprit lesions; D. Rotational atherectomy (RA) with Rotablator burr size $1.75 \mathrm{~mm}$; E. "Dogbone effect" on NC balloon $3.5 \times 15 \mathrm{~mm}$ after successful RA; F. Full expansion of ShockWave Intravascular Lithotripsy catheter after 40 pulses; G. Final angiography after drug eluting stent $(3.5 \times 38 \mathrm{~mm})$ followed by NC $4.0 \times 20 \mathrm{~mm}$ post-dilation; H, I, J. Optical coherence tomography demonstrating satisfying stent expansion and apposition. 